\title{
AC 2012-3098: INTRODUCING MIDDLE SCHOOL STUDENTS TO EN- GINEERING AND THE ENGINEERING DESIGN PROCESS
}

Linda S. Hirsch, New Jersey Institute of Technology

Ms. Suzanne L. Berliner-Heyman, New Jersey Institute of Technology

Dr. John D. Carpinelli, New Jersey Institute of Technology

John D. Carpinelli is a professor of electrical and computer engineering and Executive Director of the Center for Pre-college Programs at the New Jersey Institute of Technology. He has served as coordinator of activities at NJIT for the Gateway Engineering Education Coalition and as a member of the Coalition's Governing Board. He previously chaired NJIT's Excellence in Teaching Awards Committee and is Past Chair of the University Master Teacher Committee.

\section{Dr. Howard S. Kimmel, New Jersey Institute of Technology}

Howard Kimmel is professor of chemical engineering at New Jersey Institute of Technology in Newark, N.J., and Associate Vice President for Academic Affairs. Kimmel has been a leader in the area of precollege programs from the inception of the Center in 1980. He has directed in-service training programs for pre-college teachers for 35 years that are designed to improve the teaching of science, technology, engineering, and mathematics (STEM) in secondary and elementary schools, and to improve and enrich science and mathematics curricula and the implementation of standards-based instruction in K-12 classrooms. Kimmel has had numerous NSF grants and state grants focusing on professional development, curriculum, and assessment. In addition, he is a member of the assessment committee for chemical engineering. 


\title{
Introducing Middle School Students to Engineering and the Engineering Design Process
}

\begin{abstract}
Middle school is an important time for students to begin thinking about future careers because proper academic preparation for college must begin early for students who choose to enter the fields of science, technology, engineering and mathematics (STEM), especially engineering. Research on engineering recruitment indicates that as a result of the lack of public awareness about what engineering really is, and the absence of engineering topics in K-12 science and mathematics curricula and instruction, most potential college students are not prepared academically to study engineering in college. Summer enrichment programs designed to increase academically talented middle school students' interest in the STEM fields can be instrumental in informing young students about careers in STEM, especially engineering, so that they can appreciate the importance of obtaining the academic background required to enter college STEM programs. This paper describes such a program for fifth, sixth and seventh grade students from traditionally underserved and typically underrepresented populations who would not otherwise be exposed to engineering during their middle school years. The academic curriculum is aligned with state Core Curriculum Content Standards. Students are presented with a scenario that contains a core problem to be solved and are assigned to work in teams of four. Students receive an introduction to the Engineering Design Process (EDP), are taught how to apply the EDP in developing and testing a prototype, and are required to make a presentation about their solution to the core problem. Presentations must include an outline of how the EDP was applied and a demonstration of their prototype. Programs such as this provide an interdisciplinary, project-based learning environment that draws mostly on math, science, and technology and offers major benefits to education at all levels, as it fosters essential 21st century skills such as problem-solving, communication, teamwork, independence, imagination and creativity. Results indicate that, in addition to significant increases in their attitudes toward science, mathematics and engineering, most students demonstrated increased knowledge about careers in engineering and an understanding of the engineering design process by the end of the program.
\end{abstract}

\section{Introduction}

The demand for a highly qualified workforce in the information and knowledge age of the current global economy continues to put pressure on institutions of higher education to produce more engineers ${ }^{1}$. But despite the fact that the number of students pursuing careers in engineering has begun to increase ${ }^{2}$, this increase does not appear to satisfy the increased demand ${ }^{3,4}$. Among the many contributing factors are the underrepresentation of women ${ }^{1,5}$, a lack of public

awareness about what engineering really is ${ }^{6-9}$, and the absence of engineering topics in our K-12 science and mathematics curricula and instruction ${ }^{10-11}$.

Research on engineering recruitment indicates that most potential college students do not really know what engineers do, are unaware of the benefits that engineering provides people in their daily lives, and have few adults discussing careers in engineering with them ${ }^{6-9}$. As a result, they never develop an interest in engineering, nor are they prepared academically to study engineering 
in college. One of the more critical reasons for this is that most students, particularly those from underrepresented populations in urban school districts, are not exposed to engineering during their K-12 studies. High-quality curricular materials related to engineering, particularly for middle school students, are lacking and most teachers have not been trained to incorporate engineering topics into their curriculum and instruction. Since, unlike many professions, engineers are rarely depicted in movies or television shows, most students are not exposed to engineering outside of school. As a result, increasing the presence of engineering in K-12 education, especially through the application of science and mathematics, must become a high priority for educators ${ }^{11-12}$.

The Center for Pre-College Programs (CPCP) at New Jersey Institute of Technology (NJIT) provides a variety of summer programs designed to increase academically talented middle school students' interest in the fields of science, technology, engineering and mathematics (STEM). Programs such as these can be instrumental in informing young students about careers in the STEM fields, especially engineering, and encourage them to obtain the academic background necessary to enter a STEM program in college $\mathrm{e}^{13-14}$. One of the programs, sponsored by ExxonMobil and the Harris Foundation, the ExxonMobil Bernard Harris Summer Science Camp (EMBHSSC), recruits fifth, sixth and seventh grade students from traditionally underserved and typically underrepresented populations who would not otherwise be exposed to engineering during their middle school years. Middle school is an important time for students to begin thinking about future careers because proper academic preparation for college must begin early for students who choose to enter STEM fields, especially engineering. Because boys and girls do not differ much in technical abilities, but rather in their attitudes toward technology, until the later high school years, it is an especially important time for young girls ${ }^{15-16}$. Programs like EMBHSSC can be particularly effective in reaching young students, particularly girls, before they develop negative impressions about careers in STEM ${ }^{15-16}$.

The academic curriculum for the EMBHSSC focuses on $21^{\text {st }}$ century skills, self-efficacy and team work. At NJIT the curriculum has a space theme and is aligned with New Jersey Core Curriculum Content Standards. Students study the properties of space, analyze and predict how objects move on earth and in space, investigating how people live and survive in space. In addition to classroom lessons, students participate in hands-on activities, laboratory experiments, team-build exercises, and go on field trips. Students visit research facilities where they are introduced to engineers and have the opportunity to see first-hand the career options available to them if they should choose to study engineering.

\section{Methodology}

On the first day of camp students attend a mock "NASA Press Conference." During the press conference students are presented with the following scenario which includes a problem to be solved, (i.e. a design challenge).

"NASA has announced that in the year 2020 families will begin living in space aboard the International Space Station for extended periods of time. This means that for the first time even children will be living in space. Since these children and adults will need toys to take along, NASA has challenged all toy manufactures in the United States to design a toy that will work in space. Whichever company designs the best toy and develops the 
most effective marketing presentation will be granted an exclusive contract with NASA to begin manufacturing all the toys for the people who will be living aboard the space station. Each Toy Company not only has to design a toy that will function in space, they must provide a proof of concept prototype and develop a marketing plan to sell their toy to potential space families."

Students are given the opportunity to ask questions which lead to a discussion and lessons about the International Space Station. Students are then assigned to work in heterogeneous teams of four which become their "Toy Company" based on grade, gender and their responses to the Multiple Intelligence Test for Young People ${ }^{17}$. Students are introduced to the Engineering Design Process (EDP) and are taught how to apply the EDP in developing and testing a prototype of their toy. Each team of students is required to make a PowerPoint presentation about their toy to camp staff and parents as part of a closing ceremony at the end of the camp. Presentations include an overview of how they applied the EDP in developing their toy, a model (prototype) and demonstration of the toy, and a marketing plan, and students are expected to respond to questions.

Incorporating engineering principles, including the Engineering Design Process, into science and mathematics instruction through a problem-solving, inquiry pedagogy of this type stimulates students and helps them discover links between their lessons and engineering in the real world ${ }^{18}$. Students need to recognize that scientific inquiry answers questions about the world as it exists while engineering develops solutions to problems people encounter in everyday life.

\section{Evaluation}

Students completed a content knowledge test and the Middle School Students' Attitude to Mathematics, Science and Engineering Survey (MATE) ${ }^{9}$ at the beginning and the end of the program. The content knowledge test was used as a pretest and post-test of the concepts covered in the classroom lessons and other activities and included a question specific to the steps of the Engineering Design Process as shown in figure 1.

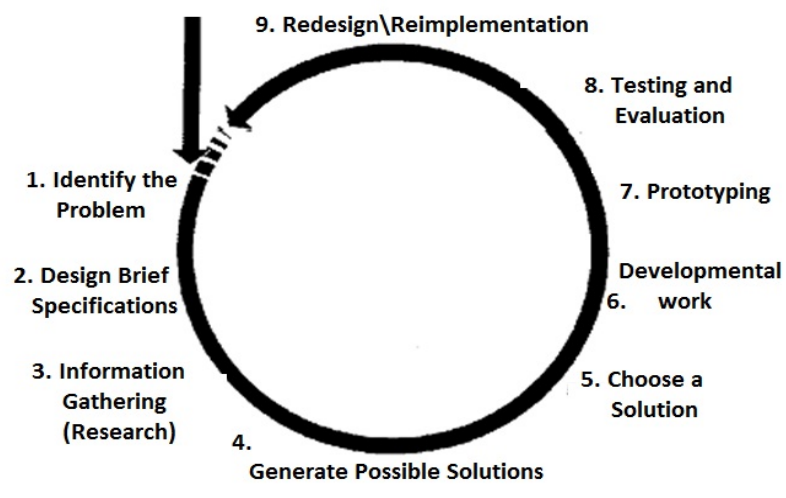

Figure 1. The Engineering Design Process

The MATE has seven subscales: Interest in engineering - stereotypic aspects (Stereotypic) (e.g. I would a job where I could help design buildings.); Interest in engineering - non-stereotypic aspects (Nonstereotypic) (e.g. I would like a job designing devices to help people walk better.); Negative Opinions and stereotypes of STEM (Negative) (e.g. Only nerds become engineers.); Positive Opinions of STEM (Positive) (e.g. Engineers help protect the environment.); Problem Solving (Problems) (I like problems that can be solved in many different ways.); Technical Skills (Technical) (I am good at technical things.); and Gender Equity (Gender) (e.g. Girls are just as good at math and science as boys.). The MATE also measures knowledge about careers in engineering with a multi-part open-ended question that requires students to "Name five different types of engineers" and to "give an example of the work done by each type". Each type is coded 
"1" for correct and "0" for incorrect. Possible total scores range from zero to five. Each example of the work they do is coded " 2 " for completely correct, " 1 " for partly correct, and " 0 " for incorrect. Possible total scores range from zero to ten.

\section{Results}

\subsection{Attitudes toward Mathematics, Science and Engineering}

Students' overall attitudes toward mathematics, science and engineering (MATE) did not increase significantly from the beginning to the end of camp (See Table I). At first this seems disappointing and one might conclude that the experience did not have much of an impact on the students' attitudes toward mathematics, science and engineering, but their average scores at the beginning of camp were already higher than for other middle school students from similar backgrounds ${ }^{9,19}$. Previous research has found that students who attended summer programs at СРCP have significantly more positive attitudes toward mathematics, science and engineering and significantly more knowledge of careers in engineering compared to other male and female students from similar backgrounds ${ }^{19}$ even before beginning the program. In order to attend any of the enrichment programs at CPCP, including the EMBHSSC, students must have a B average in school and provide letters of recommendation from their mathematics and science teachers, which means they already have positive school habits and probably like math and science but may not know about engineering. Therefore changes in their attitudes toward mathematics, science or engineering are often small and not statistically significant ${ }^{20-21}$, but often their knowledge about engineers and careers in engineering show significant increases.

TABLE I

Changes in Students' Attitudes to Mathematics, Science and Engineering Scale and Subscales From the Beginning to the End of the Summer Science Camp

\begin{tabular}{ccccc} 
& & Before Camp & End of Camp & \\
\cline { 2 - 3 } Total Scale & Mean (SD) & Mean (SD) & p-value \\
Subscales: Stereotypic & $3.7(.4)$ & $3.8(.4)$ & .73 \\
Non-stereotypic & $3.3(.7)$ & $3.3(.7)$ & .30 \\
Positive & $3.2(.7)$ & $3.4(.7)$ & .05 \\
Negative* & $3.9(.5)$ & $4.0(.6)$ & .45 \\
Problems & $2.1(.7)$ & $2.0(.8)$ & .47 \\
Technical & $4.0(.7)$ & $4.1(.7)$ & .13 \\
Gender & $3.6(.6)$ & $3.9(.6)$ & .02 \\
& $3.1 \quad(.8)$ & $3.1(.7)$ & .92 \\
\end{tabular}

* Subscale items are phrased negatively, so a lower mean score is desirable.

Examination of the subscales on the MATE did not find significant increases in students' positive perceptions about engineering or their interest in stereotypic aspects of engineering. The decrease in negative opinions and stereotypes also was not significant, although significant 
increases were found in students' interest in non-stereotypic aspects of engineering ( $\mathrm{p}=.05)$ and in their attitudes about their technical abilities $(\mathrm{p}=.02)$. The gender equity subscale did not show a significant change either and a comparison of the responses from the boys and girls separately found them to be exactly the same. But a comparison of the responses from the boys to the responses from the girls on the other subscales found some interesting significant differences.

Girls showed a significant increase in the problem solving subscale and the technical abilities subscale, where the boys did not. The average response to the problem solving questions increased from 3.9 to 4.2 for the girls $(p=.02)$ but remained 4.1 for the boys $(p=.9)$ and average response to the technical ability questions increased from 3.8 to 4.1 for the girls $(\mathrm{p}=.02)$ with a small increase from 4.0 to 4.1 for the boys $(\mathrm{p}=.45)$.

More promising were the significant increases found in students' responses to the knowledge about engineering careers question (See Table II). Forty-four percent of the students were not able to correctly name even one type of engineer before attending camp but by the end of camp most could name at least one or two types and slightly more than half (52\%) could name three or more types which is significant $\left(\chi^{2}{ }_{3}=23.7, \mathrm{p}<.01\right.$ ) (See Table II, Part 1 ). Only a small proportion (19\%) of the students were able to give even partly correct examples of the kind of work that engineers do before attending camp but by the end $85 \%$ were able to give at least some correct or partly correct examples of the kind of work a specific type of engineer does, which is also significant $\left(\chi^{2}{ }_{3}=47.5, p<.01\right)$ (See Table II, Part 2).

Table II

Changes in the Response to the Knowledge of Engineering Question From the Beginning to the End of the Summer Science Camp

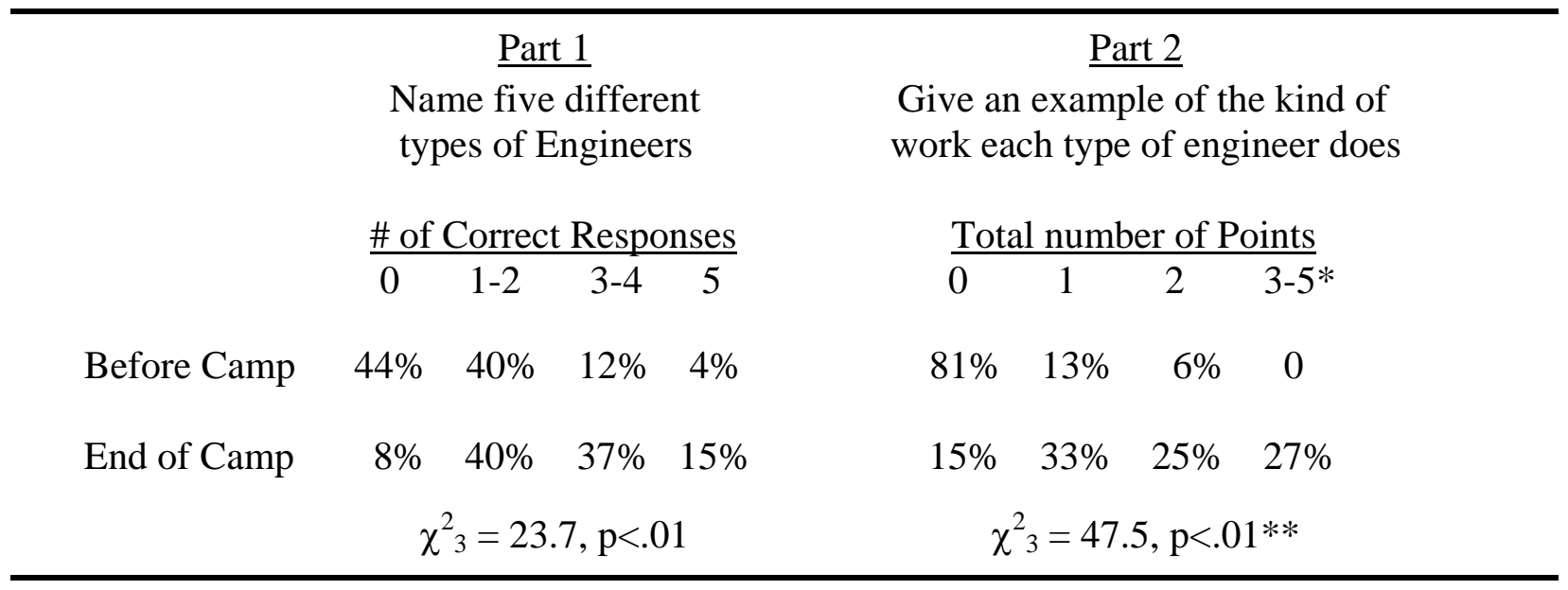

* No student scored more than 5 points out of the possible 10 .

** Categories 3, 4 and 5 were collapsed for the test.

As in prior research ${ }^{19-21}$ analysis of students' responses to the MATE showed some significant increases in students' attitudes but the results are not overwhelming, while the significant increases in their knowledge about engineers and careers in engineering are extremely positive. 


\subsection{The Engineering Design Process}

The question about the Engineering Design Process on the pre- and post-test presented students with the design circle shown in Figure 1 with nine numbered, but empty spaces and students were asked to fill in the steps of the Engineering Design Process.

Pre-test: Sixty percent of the students made no attempt to fill in any of the steps. Only three of the 54 students indicated that the process starts by Identifying a Problem, two more students suggested it started with a question. The remaining students did not mention the statement of a problem or the posing of a question in any of the subsequent steps either. Only seven students used the expression "Brainstorming" and most of them indicated it was the first step. The most common response in the first few steps was "Plan”. Four students used the word "hypothesis". Only six students indicted research in any of the steps and they were not necessarily the same four who suggested a hypothesis. Building, planning, checking, organizing, experimenting and measuring were suggested in various different orders with finishing, selling, presenting and publishing offered as final steps. Ten students suggested testing or revising but only one mentioned both testing and revising. Many repeated the same step more than once and the term "prototype" was used by only eight students.

One student offered three steps: Plan, Design, Test. The steps presented by the three students who suggested the process began by Identifying a Problem were:

1) Find a problem, Find a Solution, Plan, Test it, Prototype, Test, Edit, Present, Sell.

2) Finding a Problem, Brainstorm, Write an idea, Plan idea, Build Stuff, Prototyping, Trial test, Completion and Distribution.

3) State Problem, Brainstorm, Design, Think of Counter Reaction, Build.

Post-test: Only three of the students did not attempt to fill in any of the steps on the post-test. Almost eighty percent of the students correctly indicated that the process starts with a Problem. And of those students all but one indicated that the second step was a 'design brief with specifications'. Of the $80 \%$ who correctly identified the first two steps, all but six indicated that the third step was either: "research, investigation, or information gathering”. Some skipped this step or indicated it was the fourth step. Sixty-two percent indicated the fourth step was to generate possible solutions and then choose a solution as the fifth step. Another 10\% indicated either or both of these steps out of order, such as in the third and forth steps, and some only mentioned solutions in one of the steps.

Fifty percent of the students correctly identified Developmental work as the sixth step after correctly identifying the first 5 steps. Another 15\% indicated developmental work in another step. Sixty-two percent of the students indicated the seventh step was Prototyping. Another 25\% indicated prototyping in a different step such that most of the students, even those who did not provide correct answers to most of the other steps, recognized the importance of a prototype. This is further supported by the fact that almost $90 \%$ of the students also provided an accurate answer to the question "What is a prototype?" on the post-test. Sixty percent indicated either testing, evaluation or both testing and evaluation as the eighth step, with an additional $20 \%$ who indicated them as either the seventh or final step. And finally 65\% indicated that Redesign was 
the final step. Fifteen percent indicated redesign in an earlier step and indicated things like, present, sell, patent or mass produce as the final step. Perhaps this is related to the fact that as part of the program students were required to make a presentation about their toy design. Some teams even made up a commercial to sell their toy as part of their presentation.

\section{Discussion and Conclusion}

Although most of the increases in students' attitudes were not significant, results of the current study are very positive. As was found in previous research, it appears that while attitudinal measures such as those provided by the MATE are useful measures of the effectiveness of most pre-engineering curriculum materials ${ }^{22}$ or STEM enrichment programs ${ }^{19}$ they are not necessarily the most effective measures of change that results from programs designed for high achieving students, such as those who attend the EMBHSSC, that require good grades and teachers recommendations ${ }^{20-21}$. The knowledge about engineers and careers in engineering question appears more informative as are other less objective measures of changes in students' perceptions of engineers and engineering ${ }^{23-24}$. Significant increases were found in students' knowledge about careers in engineering and their attitudes about their own technical abilities, particularly for girls.

Based on the results of the pre-post content knowledge test it is clear that attending the ExxonMobil Bernard Harris Summer Science camp provided most of the students with an understanding of the Engineering Design Process. Most of the students were able to identify a process that started with the identification of a problem that required some investigation, consideration of alternative solutions, building a prototype and then testing and evaluating the prototype. Although many of their answers presented the steps as we taught them somewhat out of order, they understood the basic process and identified most of the steps.

Even though summer enrichment programs of this type tend to be intensive and short students often come away from them with positive attitudes and more motivation for the coming school year. Result from the current study indicate that middle school students even as young as the fifth grade can learn and apply the Engineering Design Process and that exposing them to the EDP, either through programs such as this or during the regular school year, is one way to encourage more students to explore and possibly become more interested in engineering.

\section{Acknowledgements}

The ExxonMobil Bernard Harris Summer Science Camp at New Jersey Institute of Technology is funded by a grant from The Harris Foundation and ExxonMobil Corporation.

Bibliography

1. ehow.com/list_7395677_types-engineers-job-descriptions.html

2. National Science Board. Science and engineering indicators 2010, Arlington, VA: National Science Foundation, 2010 (NSB-00-1). 
3. JobWeb.com - Career development and job search help for college students. Copyright National Association of Colleges and Employers.

4. American Society of Engineering Education. Engineering Education and the Science \& Engineering Workforce. Public Policy Internet Website. http://www.asee.org.

5. New Jersey Commission on Higher Education. Higher education outcomes and high-tech workforce demands. The fifth annual system wide accountability report. 2001.

6. National Academy of Engineering. Raising Public Awareness of Engineering. The National Academies Press. Washington, D.C. 2002.

7. Gibbons, S. J., Hirsch, L. S., Kimmel, H., Rockland, R. and Bloom, J. (2003). “Counselors Attitudes and Knowledge About Engineering”. Proceedings of the 2003 International Conference on Engineering Education, Valencia, Spain, July 2003.

8. Hirsch, L. S., Gibbons, S. J., Kimmel, H., Rockland, R. and Bloom, J. (2003). "High School Students Attitudes to and Knowledge About Engineering”. Proceedings of the $33^{\text {rd }}$ ASEE/IEEE Frontiers in Education Conference, Boulder, CO, November 2003.

9. Gibbons, S. J., Hirsch, L. S., Kimmel, H., Rockland, R. and Bloom, J. (2004). "Middle School Students Attitudes to and Knowledge About Engineering”. Proceedings of the 2004 International Conference on Engineering Education, Gainesville, FL, October 2004.

10. Kimmel, H., Carpinelli, J., Burr-Alexander, L., and Rockland, R. "Bringing Engineering into K-12 Schools: A Problem Looking for Solutions?” Proceedings of the 2006 ASEE Annual Conference, Chicago, IL, June 2006.

11. National Science Board (2008). Science and engineering indicators 2008, Arlington, VA: National Science Foundation (NSB-08-1).

12. Kimmel, H., and Rockland, R. (2002). "Incorporation of Pre-Engineering Lessons into Secondary Science Classrooms". Proceedings of the $32^{\text {nd }}$ ASEE/IEEE Frontiers in Education Conference, Boston, MA, November 2002.

13. Cano, R., Kimmel, H., Koppel, N., and Muldrow, D. (2001). “A First Step for Women into the Engineering Pipeline”. Proceedings of the $31^{\text {st }}$ ASEE/IEEE Frontiers in Education Conference, Reno, NV, October 2001.

14. Hirsch, L. S., Kimmel, H., Rockland, R. and Bloom, J. (2007). “The Differential Effects of Female Only vs. CoEd Enrichment Programs on Middle School Students' Attitudes Toward Science, Mathematics and Engineering”. Proceedings of the 2007 ASEE Annual Conference, Honolulu, HI, June 2007.

15. Hofman, H. "Engineering as a career choice: Strengthening the weakest link”. WEPAN National Conference, 2000. $137-143$

16. Blaisdell, S. “Students' decision to enter engineering: How men and women differ.” WEPAN Annual Conference, 2000. 243-251.

17. Multiple Intelligence Test for Young People. http://www.businessballs.com/freepdfmaterials/free_multiple_intelligences_test_young_people.pdf.

18. Hirsch, L. S., Carpinelli, J., Gibbons, S. J., Kimmel, H., Rockland, R. and Bloom, J. (2007). The Differential Effects of Pre-engineering Curricula on Middle School Students' Attitudes to and Knowledge of Engineering Careers. Proceedings 37 $7^{\text {nd }}$ ASEE/IEEE Frontiers in Education Conference, Milwaukee, WI, October 2007. 
19. Cano, R., Berliner-Heyman, S., Koppel, N., Gibbons, S., and Kimmel, H. (2004). "Evaluation of Summer Enrichment Programs”, Proceedings of the 2004 American Society for Engineering Education Annual Conference \& Exposition, Salt Lake City, UT, June 2004.

20. Hirsch, L. S., Kimmel, H., Rockland, R. and Bloom, J. (2006). “A Study of the Impact of Enrichment Programs on Girls' Attitudes Towards Engineering”. Proceedings of the 2006 International Conference on Engineering Education, San Juan, PR, July 2006.

21. Harwood, J. \& Rudnitsky, A. (2005). Learning About Scientific Inquiry through Engineering. Proceedings of the 2005 ASEE Annual Conference, Portland, OR, June 2005.

22. Kimmel, H., Carpinelli, J., Burr-Alexander, L., Hirsch, L. and Rockland, R. "Introducing Robotics into the Secondary Science Classrooms," Proceedings of the $19^{\text {th }}$ International SITE Conference, pp. 4189-4194, Las Vegas, NV, March 2008.

23. Hirsch, L. S., Berliner-Heyman, S., Cano, R., Kimmel, H., and Carpinelli, J., "Middle School Girls' Perceptions of Engineers Before and After a Female Only Summer Enrichment Program". Proceedings of the 2011 ASEE Frontiers in Education Annual Conference, Rapid City, South Dakota, October 2011.

24. Hirsch, L. S., Berliner-Heyman, S., Kimmel, H., and Carpinelli, J. "Middle School Students' Perceptions of Engineers Before and After a Summer Enrichment Program”. Proceedings of the 2011 International Conference for Engineering Education, Belfast, Northern Ireland, August 2011. 